\title{
Numerical Investigation of the Internal Flow in a Banki Turbine
}

\author{
Jesús De Andrade, Christian Curiel, Frank Kenyery, Orlando Aguillón, \\ Auristela Vásquez, and Miguel Asuaje
}

\author{
Laboratorio de Conversión de Energía Mecánica, Universidad Simón Bolivar, Valle de Sartenejas, \\ Caracas 1080, Venezuela
}

Correspondence should be addressed to Jesús De Andrade, jesusandrade@usb.ve

Received 12 October 2010; Revised 23 February 2011; Accepted 7 July 2011

Academic Editor: Forrest E. Ames

Copyright ( 2011 Jesús De Andrade et al. This is an open access article distributed under the Creative Commons Attribution License, which permits unrestricted use, distribution, and reproduction in any medium, provided the original work is properly cited.

\begin{abstract}
The paper refers to the numerical analysis of the internal flow in a hydraulic cross-flow turbine type Banki. A 3D-CFD steady state flow simulation has been performed using ANSYS CFX codes. The simulation includes nozzle, runner, shaft, and casing. The turbine has a specific speed of 63 (metric units), an outside runner diameter of $294 \mathrm{~mm}$. Simulations were carried out using a waterair free surface model and $\mathrm{k}-\varepsilon$ turbulence model. The objectives of this study were to analyze the velocity and pressure fields of the cross-flow within the runner and to characterize its performance for different runner speeds. Absolute flow velocity angles are obtained at runner entrance for simulations with and without the runner. Flow recirculation in the runner interblade passages and shocks of the internal cross-flow cause considerable hydraulic losses by which the efficiency of the turbine decreases significantly. The CFD simulations results were compared with experimental data and were consistent with global performance parameters.
\end{abstract}

\section{Introduction}

Small hydroelectric power plants $(P<10 \mathrm{Mw})$ are a solution to the power needs of small communities. The cross-flow turbines may gain acceptance, and as they can be used in these power plants due to their simple construction, low cost of initial investment and modest efficiency $(\sim 84 \%)$.

The utilization of these turbines in large-scale power plants has been limited due to its low efficiency compared to other turbines used commercially $(\eta>90 \%)$. In order to make them more competitive, it is imperative that their efficiency be improved. This can only be achieved by means of studying the turbine operation and determining the parameters and phenomena that affect their performance. Nowadays, numerical tools are regarded as an industry standard for this process.

The improvements in CFD tools have allowed the modeling and obtaining of numerical accuracy of flow fields in turbomachines than previously attained. Turbomachinery designers regularly use numerical methods for predicting performance of hydraulic reaction pumps [1] and turbines [2]. However, numerical methods for predicting the action turbine performance with free surface flow conditions have slowly emerged due to the complex nature of this physic phenomenon.

One-dimensional (1D) and quasi-three-dimensional (Q3D) approaches for turbomachinery design and analysis can be considered well adapted and powerful enough for most applications. Researchers such as Mockmore and Merryfield [3] have used 1D theoretical analysis methods and experiments to improve the cross-flow turbines performance. However, for designing a high-performance Banki turbine, it is necessary to determine accurately the internal flow in the static passages and the cross-flow within the runner [4]. In the literature, CFD simulation results with regard to nozzle flow are consistent with experimental results. Pereira and Borges [5] presented a 2D-CFD investigation of the water flow inside the nozzle. The numerical results are consistent with the experimental data collected when the runner was not present. This approach has also been used by Marchegiani and Montiveros [6], where the effect of the turbine injector geometry is studied. In another approach by Arzola et al. [7], 3D free surface flow simulations (i.e., waterair) inside a nozzle were performed. With this approach, 
certain differences were found between water and water-air CFD results with regard to the flow velocity angles towards the 1st stage of the runner.

Another method has been developed by Chávez and Vera [8], which considers a $2 \mathrm{D}$ water flow simulation of the domains nozzle, runner 1st stage, and 2nd stage separately. Global performance parameters were presented for different operating conditions. Fukutomi et al. [9, 10] have investigated through 2D numerical calculations the unsteady water flow inside the runner, paying attention to the flow along the runner entrance and unsteady forces on the blades.

On the other hand, Choi et al. [11] performed an entire 2D-CFD steady state cross-flow turbine simulation, considering water and water-air flow conditions. With this approach, the authors studied the influence of nozzle shape, runner blade angle, and runner blade number on the turbine performance. Moreover, the important role of the air layer on the numerical calculation was verified.

The purpose of the present study is to perform a 3DCFD steady state flow simulation of a hydraulic cross-flow turbine type Banki (including nozzle, runner, shaft, and casing) in order to analyze and understand the fluid dynamic behavior of the multiphase flow within the runner. The study is focused on achieving a better use of small hydraulic resources with future cross-flow turbine designs. The specific objectives of the study are to:

(i) determine the flow field inside the nozzle-casing assembly of the turbine in order to obtain the flow velocity angles $\alpha$ that could be found in the runner inlet (1st stage),

(ii) reproduce a full simulation of the turbine and characterize its performance and to compare the numerical results with previous experimental data,

(iii) analyze the velocity and pressure fields of the crossflow within the runner,

(iv) conclude on the influence of including the runner in the numerical calculations.

\section{Cross-Flow Turbines}

An extensive bibliographical review on the development of the cross-flow turbines can be found in the works of Khosrowpanah et al. [12], Fiuzat and Akerkar [13, 14] and Venkappayya and Nadim [15]. The works included details concerning the influence of the number of blades, outside diameter of the runner and admission arc of the nozzle on the turbine efficiency.

Fiuzat and Akerkar [13] led a study to improve the crossflow turbine efficiency by means of using a guide tube inside the runner to collect and guide the flow that crosses the interior towards the 2nd stage of the runner. In their study, these authors conclude that the low efficiency of the turbine is attributed to a certain portion of the flow that crosses the runner blade being lost in the 2nd stage leaving it without transferring energy; this flow only generates power in the 1st stage. A scheme of this flow distribution is shown in Figure 1.

Furthermore, Fiuzat and Akerkar [14] carried out another study with the intention of identifying the contribution

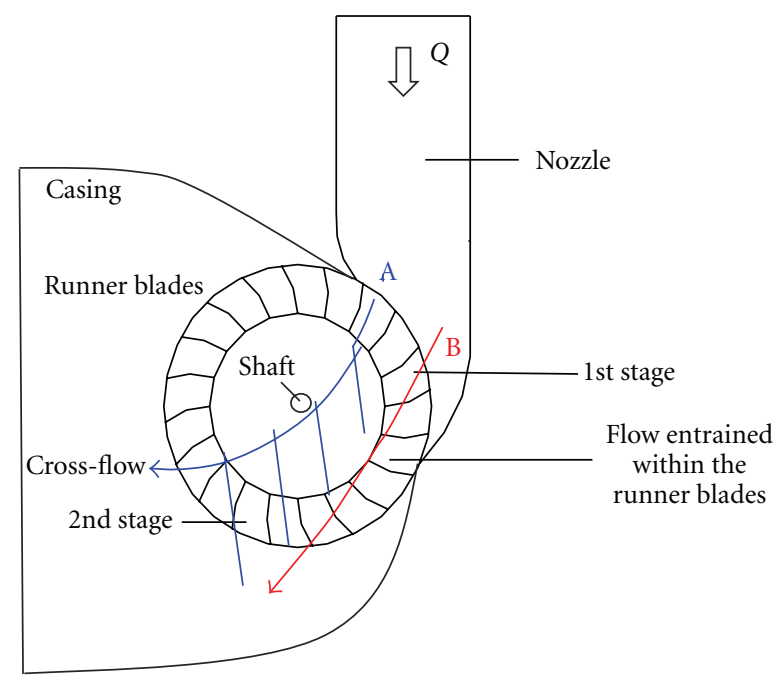

Figure 1: Flow distribution within the runner of a cross-flow turbine.

of each one of the cross-flow turbine stages to the power output generation. The authors conclude, after this study, that the 2 nd stage plays a significant role in the total efficiency of the cross-flow turbine, which could be increased if the research carried out by Nakase et al. [16] is considered. They established that the flow in a Banki turbine is divided in two types of flow, as can be observed in Figure 1. The flow in zone " $\mathrm{A}$ " is deflected by the blades in the 1st stage and afterward deflected by 2 nd stage, thereby transferring energy to each of the runner stages; this flow is denominated "crossflow". The flow of zone " $\mathrm{B}$ " is dragged within the blades and is denominated "non-cross-flow". Increasing the amount of water that flows through zone " $A$ " increases the efficiency of the turbine. This would not improve the efficiency of the 1st stage, but it would increase the cross-flow towards the 2 nd stage.

Shepherd [17] comments that with cross-flow turbines $75 \%$ of the available energy is transferred with greater efficiency in the 1st stage, when the water flows towards the interior of the runner blade, and the remaining $25 \%$ is transferred with lesser efficiency in the 2nd stage, when the water flows in the opposite direction.

The hydraulic efficiency of the 1st stage is greater because the angle of incidence of the fluid $\alpha_{1}$ can be calculated and controlled with an appropriate nozzle design. In the 2nd stage the efficiency falls due to the hydraulic losses that take place inside the runner. The flow angles at the inlet of this 2nd stage cannot be controlled. Figure 2 shows for different streamlines, the velocity triangles when the flow is coming out of the 1st stage of the runner blade. As can be observed, the absolute velocity $V_{2}$ has different directions for each blade and the streamlines tend to "collide" inside the runner.

2.1. Calculation of Effective Head and Efficiency. The effective turbine head is given by the application of the Euler equation, which expresses that the energy acquired from the fluid that flows through the runner is a function of the angular 


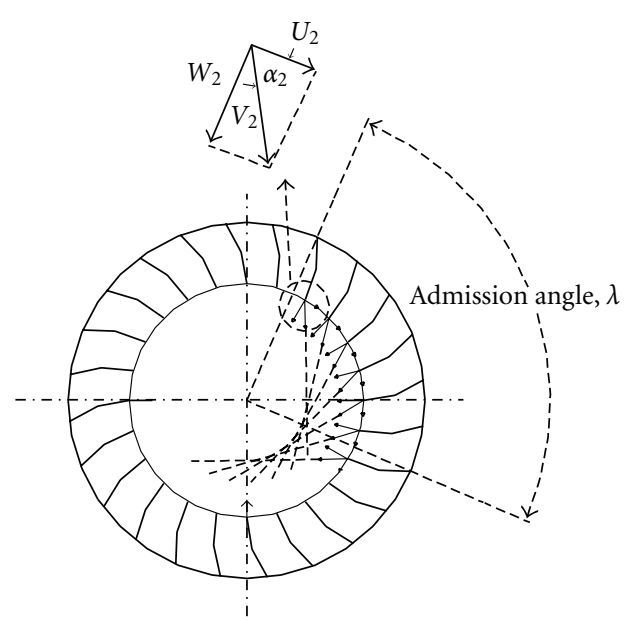

Figure 2: Streamlines intersection at 1st stage outlet of the Banki turbine.

moment variation. In the cross-flow turbine case, the Euler equation can be expressed as follows:

$$
H_{t}=\frac{1}{g}\left[\left(U_{1} V_{u 1}-U_{2} V_{u 2}\right)+\left(U_{3} V_{u 3}-U_{4} V_{u 4}\right)\right]
$$

The Euler equation considers the variation of the velocity triangles from runner inlet to outlet of the 1st stage and then from runner inlet to outlet of the 2 nd stage. The relevant velocity triangles within the runner are schematized in Figure 3. According to the figure, for design conditions $\alpha_{2}=\alpha_{3}, W_{2}=W_{3}$ and $\beta_{3}=90^{\circ}$. In addition, a good design requires that $\alpha_{1}$ should be between 15 and $20^{\circ}$ [3].

The global efficiency of the turbine is given by (2). Furthermore, for this study it is important to mention the hydraulic efficiency, which considers the losses due to hydraulic effects. The hydraulic efficiency can be expressed as

$$
\begin{gathered}
\eta=\frac{P_{\text {hydraulic }}}{P_{\text {shaft }}}, \\
\eta_{h}=\frac{H_{t}}{H} .
\end{gathered}
$$

\section{Test Case}

A hydraulic cross-flow turbine with a specific speed of 63 (metric units) is used as the test object. During the 1980's this turbine was part of a test facility of the Mechanical Energy Conversion Laboratory at "Universidad Simón Bolívar". This facility was designed to characterize the performance of the turbine [18]. Through the tests were obtained the global performance parameters of the turbine for different runner speeds, at each flow rate and head tested. With the processing of all this data, the hill diagram of the turbine was constructed. The design flow parameters of the turbine were a head of $35 \mathrm{~m}$, a flow rate of $0.135 \mathrm{~m}^{3} / \mathrm{s}$ and a speed of $800 \mathrm{rpm}$. Other relevant parameters are presented in Table 1.
TABLe 1: Design parameters for the cross-flow turbine used as test object.

\begin{tabular}{lccc}
\hline \multicolumn{4}{c}{ Specifications of the Banki turbine } \\
\hline$\beta_{1}$ & $120^{\circ}$ & $\alpha_{1}$ & $16^{\circ}$ \\
$\beta_{2}$ & $90^{\circ}$ & So & $46 \mathrm{~mm}$ \\
$D_{\text {out }}$ & $294 \mathrm{~mm}$ & $\lambda$ & $70^{\circ}$ \\
$D_{\text {ins }}$ & $200 \mathrm{~mm}$ & $\eta$ & $71 \%$ \\
$B$ & $150 \mathrm{~mm}$ & $z$ & $24 \mathrm{blades}$ \\
$d$ & $48 \mathrm{~mm}$ & $r$ & $46 \mathrm{~mm}$ \\
\hline
\end{tabular}

\section{Numerical Approach}

Due to the great computational costs and time that the study of this complex flow through the turbine entails, all the simulations were carried out at the design conditions $(H, Q)$ varying the runner speed.

$3 \mathrm{D}$ viscous steady CFD simulations are performed by using the commercial software ANSYS CFX v.11. As turbulence model, $\mathrm{k}-\varepsilon$ turbulence model closure with scalable wall functions is used. This near-wall treatment can be applied on arbitrarily fine grids and allows the user to perform a consistent grid refinement independent of the Reynolds number of the application. More details can be found in [19]. Given that the flow considered in this study is a two-phase flow (water-air), where the fluids are separated by a distinct interface, the standard homogeneous free surface model is used. Thus, both fluids share the same velocity, pressure, and turbulence fields. It was not possible to apply the buoyancy model, since the software does not allow it when there is a numeric domain in rotation, such as the runner. More details of the numerical modeling can be found in [20,21].

The viscous fluxes are computed with a "high-resolution" scheme, which means that in regions with low variable gradients, a second order upwind scheme is used. In areas where the gradients change sharply, a first-order upwind scheme is used to maintain robustness. Besides, root mean squared convergence criteria with an average residual target of $1 \times 10^{-4}$ in mass, momentum and turbulence $(\mathrm{k}-\varepsilon)$ equations is used. The boundary conditions are as follows:

(i) inlet: velocity normal to face, $\alpha v_{\text {water }}=1$ and $\alpha v_{\text {air }}=$ 0 ,

(ii) outlet: static pressure, type opening, $\alpha v_{\text {water }}=0$ and $\alpha v_{\text {air }}=1$,

(iii) periodic: two symmetry surfaces positioned in the middle of the blade passages,

(iv) wall: general boundary condition by default (noslip).

Regarding the numerical treatment between the Nozzle/Runner/Casing interfaces, the type "frozen rotor" was set. This means that the frame of reference is changed, but the relative orientation among the components across the interface is fixed. This model produces a "steady state" solution to the multiple frame of reference problem, with some account of the interaction between the two frames. This analysis 


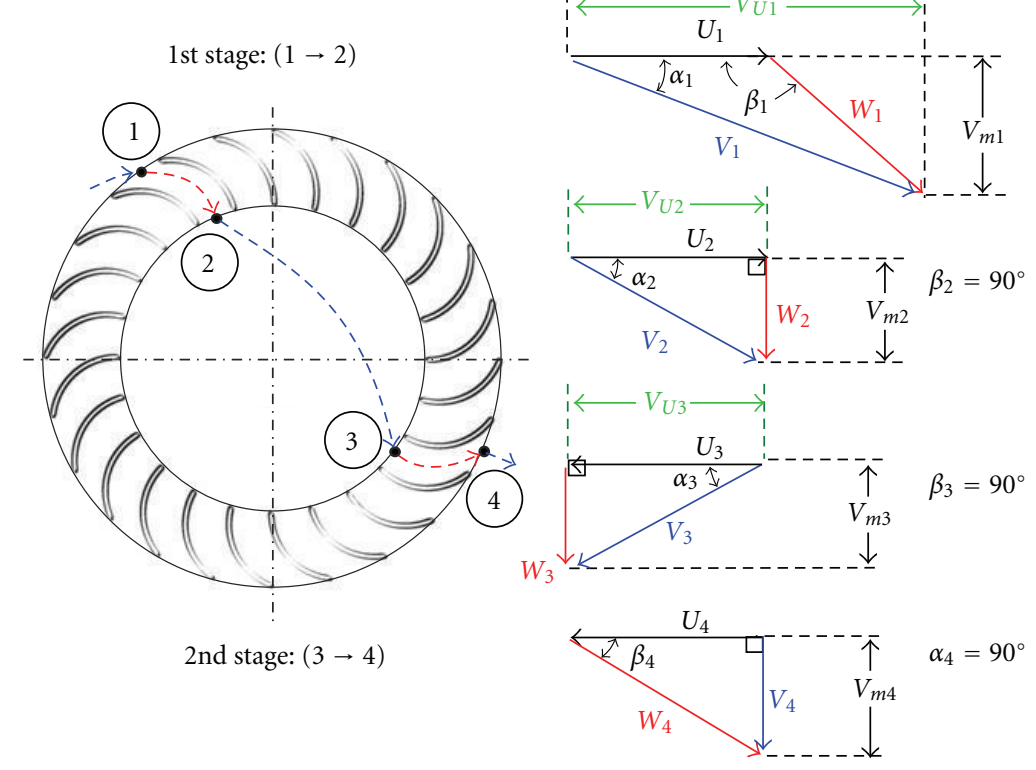

Figure 3: Theoretical velocity triangles of a cross-flow turbine runner.

is useful when the circumferential variation of the flow is large. The disadvantages of this model are that the transient effects at the frame change interface are not modeled and the flow field results are related to a unique position between nozzle/runner/casing domains. More details are in [22].

In order to conclude on the effect of including the runner on the calculation of the absolute flow velocity angles $\alpha$ that would come to the runner inlet (1st stage), two numerical flow domains are studied:

(i) domain I: conformed by the nozzle and casing of the turbine

(ii) domain II: conformed by nozzle-runner-casing.

For the runner, a structured grid was created using the Turbogrid v.1.06 ANSYS software. For the rest of fluid domains, unstructured tetrahedral grids with inflated layers at the walls were created. As in any CFD simulation, a sensibility analysis was performed to guarantee that results are not dependent on grid size. Figure 4 shows how the calculated pressure drop reaches an asymptotic value as the number of elements increases. According to this figure, the grids highlighted are considered to be sufficiently reliable to ensure mesh independence. The total number of elements inside domain I was 1,220,070 and for domain II was $1,413,985$. 3D views of domains I and II, including all the meshes, are shown in Figure 5. Table 2 presents the detailed number of elements in each domain. The closest nodes to the solid walls are located at a distance of between 0.2 to $1 \mathrm{~mm}$, given y plus values bellow 200 .

For both domain cases (I and II) the rotation angle $\theta$ is employed in order to assess flow angles and velocities of interest for this study. The $\theta$ angle is measured from the beginning of the nozzle in an anticlockwise direction. Details of $\theta$ angle measuring and cylindrical coordinate system with origin at the centerline of the runner are shown in Figure 6.
The radial unit vector shown on the figure is considered positive regarding the radial velocities further addressed in this study.

For the validation of this numerical investigation, the conducted CFD computations are compared to global performance parameters. The parameters considered are global and hydraulic efficiency. The experimental efficiency is calculated according to (2) and the numerical efficiency according to (3), which means that the volumetric and mechanical efficiencies are not numerically estimated.

\section{Results and Discussion}

5.1. Nozzle-Casing Flow Field Analysis (Domain I). In this first part of the results section two main issues are addressed for the design test conditions $(H, Q)$ : firstly, the analysis and discussion of the multiphase flow field with respect to waterair volume fraction and water velocity variations at midspan location. Secondly, the investigation of the absolute flow velocity angles $\alpha_{1}$ variations that would come to the runner inlet (1st stage). The study is conducted for the assembly nozzle-casing, but focusing on the nozzle outlet.

In Figures 7 and 8, the water volume fraction contour and water velocity vectors at the midspan are, respectively, illustrated for the flow design condition. A free surface flow with a well-defined interface between the water and air homogenous flows can be observed. The water flow velocity field reaches the maximum velocities at nozzle outlet, where the runner 1st stage inlet would be. The transfer of energy from pressure into speed is important in any action turbine. However, according to (3), maintaining a specific flow angle at runner entrance is of equal importance.

In Figure 9, the $\alpha_{1}$ angle is plotted against the rotation angle occupied by the admission angle $\lambda$ of the nozzle. Water volume fraction variation is also shown. It can be seen that the $\alpha_{1}$ angle decreases from $23^{\circ}$ by increasing the 


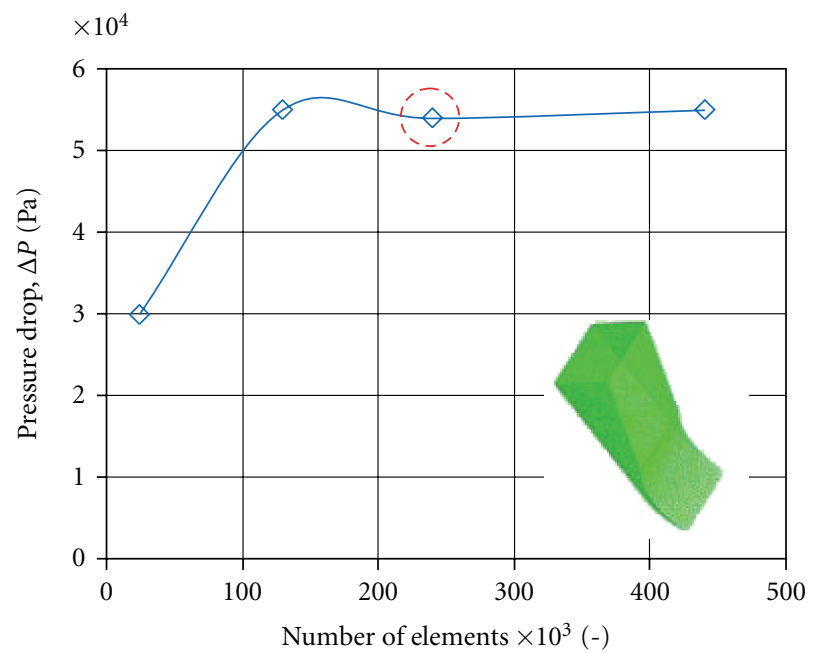

(a)

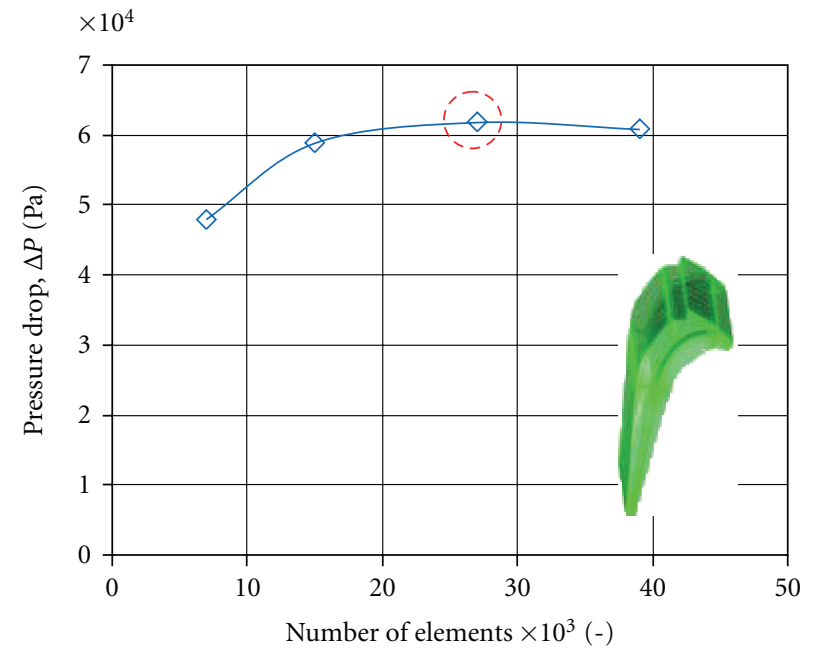

(b)

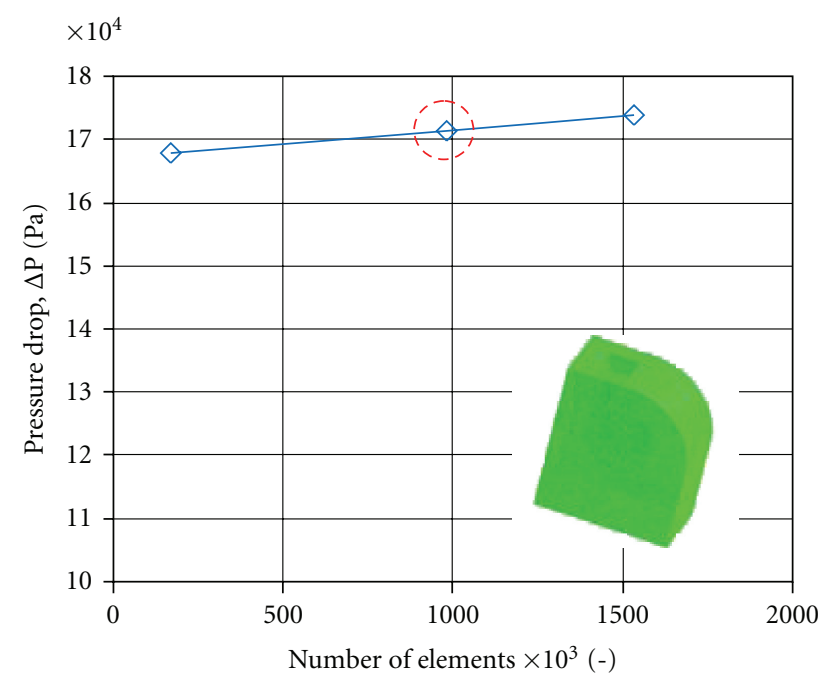

(c)

FIGURE 4: Influence of grid size on (a) nozzle, (b) runner blade passage, and (c) casing pressure drop.

TABLe 2: Number of elements and characteristics of meshes.

\begin{tabular}{|c|c|c|c|c|c|}
\hline \multirow[b]{2}{*}{ Mesh Block } & \multicolumn{2}{|c|}{ Domain I } & \multicolumn{3}{|c|}{ Domain II } \\
\hline & Nozzle & Casing & Runner & Nozzle & Casing \\
\hline Nr. of meshes in subdomain & 1 & 1 & 24 & 1 & 1 \\
\hline Nr. of elements by mesh & 240,048 & 980,022 & 27,040 & 240,000 & 525,025 \\
\hline Grid skew & - & - & $15-165$ & - & - \\
\hline Grid element volume ratio & 16 & 19 & 14 & 18 & 22 \\
\hline
\end{tabular}

rotation angle until it reaches the middle of the admission angle, where it rises gradually until almost the end of this angular sector, where it declines sharply to $7^{\circ}$. The numerical grid could account, at least partially, for some of the small oscillations seen in $\alpha_{1}$ angle. Nevertheless, according to the grid validation in Figure 4 the numerical grid selected not seems to influence the turbine performance noticeably. The observed trend is not an obvious fact, as the design $\alpha_{1}$ is $16^{\circ}$. Arzola et al. [7] found a similar absolute flow velocity angle variation in their study. The explanation for this flow behavior is probably the standard supposition of potential flow when the nozzle was designed. Furthermore, 


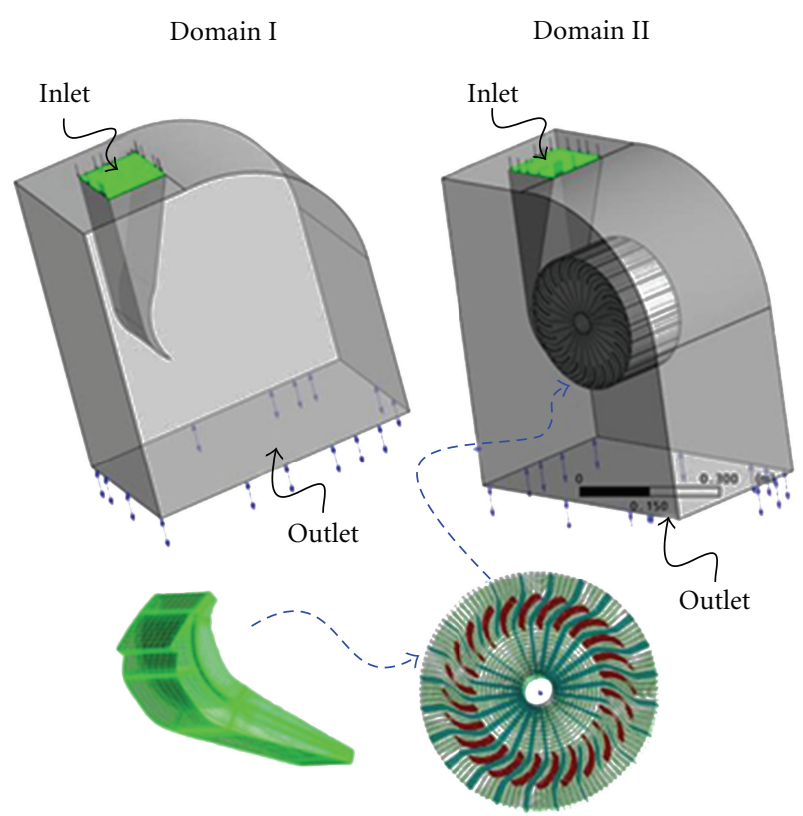

FIGURE 5: 3D views of the numerical domains I and II.

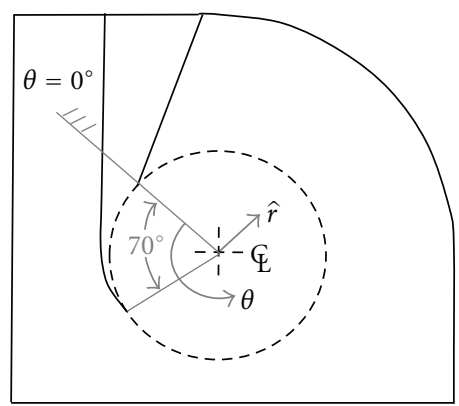

FIGURE 6: Schematic view of rotation angle $\theta$ measuring and general cylindrical coordinates.

it is observed that the water volume fraction rises sharply to 1 by increasing the rotation angle from 0 to $5^{\circ}$.

5.2. Cross-Flow Turbine Flow Field Analysis (Domain II). In this section, the fluid dynamic behavior of the cross-flow turbine is addressed for the design test conditions $(H, Q)$. First, the 1 st and 2 nd runner stages are quantitative studied for the design runner speed. Next, the assessment of the numerical and experimental calculations by comparing the global performance parameters for different runner speeds is presented. Furthermore, the water volume fraction and water flow velocity contours are addressed for different runner speeds. Particular attention is paid to the nominal speed. Next, the significant absolute and relative flow velocity angles are investigated for the 1 st and 2 nd runner stages at design speed. Finally, the absolute flow velocity angles found for domains I and II are compared.

Definition of Runner Stages. To estimate the cross-flow turbine hydraulic efficiency through the CFD simulations on
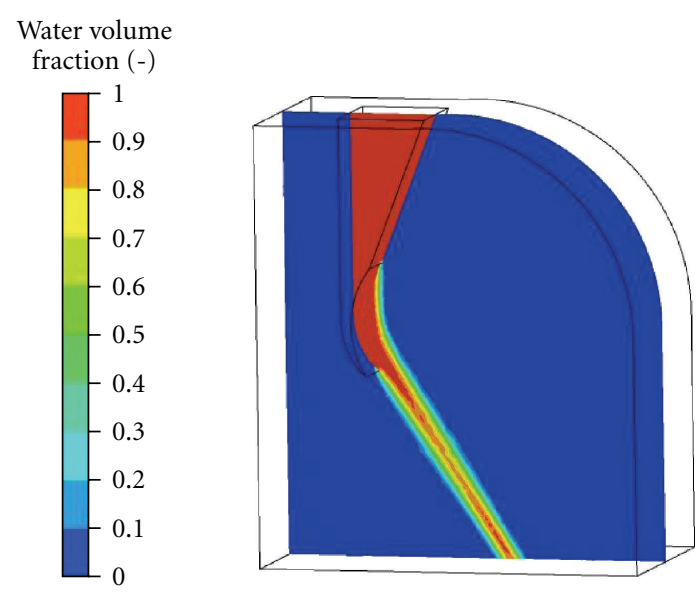

Figure 7: Water volume fraction contour at midspan of domain nozzle casing.

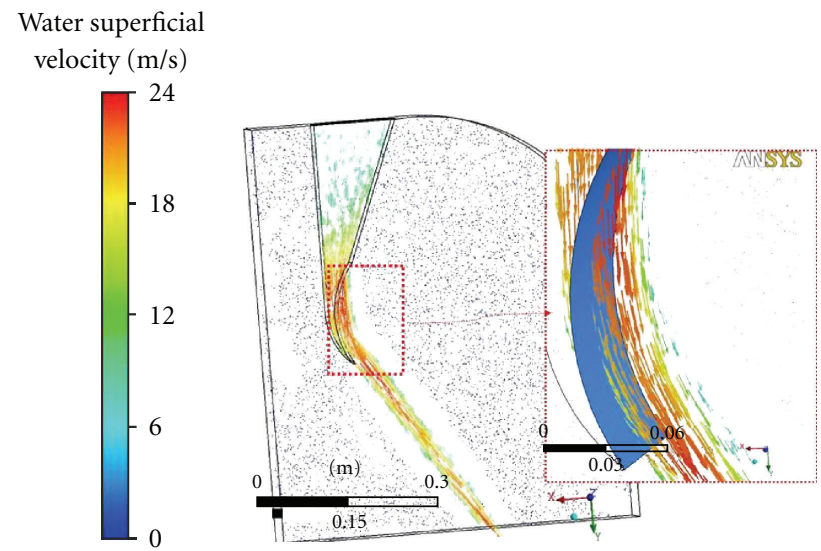

FIGURE 8: Water superficial velocity vectors at midspan of domain nozzle casing.

Domain II, it is important to establish clearly the angular limits at each stage of energy transfer. Considering the variation of water radial velocities and water volume fraction in the rotation runner angle " $\theta$ " at the inside diameter, the 1st and 2nd stage can be established. In this section, the calculated variations of the radial water velocity and water volume fraction along a specific rotation sector at the runner outside diameter $\mathrm{D}_{\text {out }}$ are addressed in order to determine the 1 st and 2 nd stage of the runner at design speed. The results plotted in Figure 10 are obtained for the cross-flow turbine at midspan location.

The water volume fraction rises sharply to 1 at the beginning of the rotation angle, maintaining this value until it reaches approximately $\theta=70^{\circ}$, where the volume fraction slopes downwards to 0.23 . Suddenly the water volume fraction starts to rises sharply and reaches 1 again at $\theta \approx 75^{\circ}$. This result represents the angular sector between the 1 st and $2 \mathrm{nd}$, stage where there is a minimum water flow. Finally, the water volume fraction rises again to 1 until $\theta=124^{\circ}$, where the water volume fraction decreases 


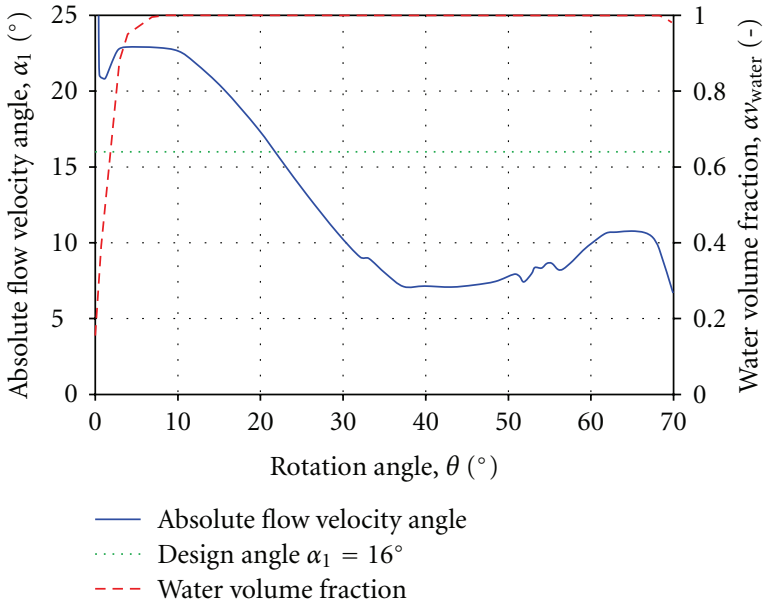

Figure 9: Absolute flow velocity angle and water volume fraction along the rotation angle at midspan of nozzle-casing domain.

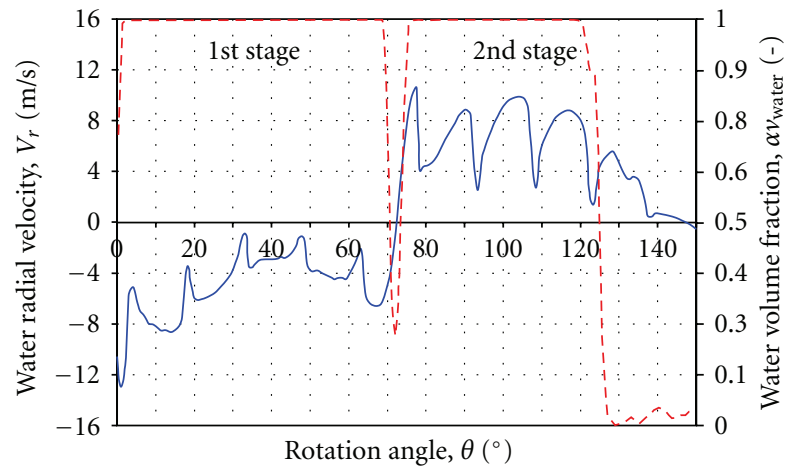

- Water radial velocity

- - - Water volume fraction

Figure 10: Water radial velocity and water volume fraction variations for a specific $\theta$ range along the outside runner diameter.

abruptly to approximately 0 . Therefore, the 1 st and 2 nd stage of the runner could be established between the angular sectors, where the water volume fraction is approximately 1 . Figure 10 shows the 1 st and 2 nd stage for the design runner speed.

In addition, negative radial velocities for the 1st stage and positive radial velocities for the 2 nd stage of the runner can be seen in Figure 10. This represents the inlet flow of the 1st stage and outlet flow to the 2 nd one, respectively. It was observed that the radial velocity downwards peaks sources are, for 1st stage, the periodical flow wakes downstream after each blade trailing edge. For the 2 nd stage, the peaks are due to the periodical impacts of the flow that leaves the 1st stage and shocks against the blades leading edges of 2 nd stage. This leads to considerably higher velocity perturbations. After each wake or shock location, the water radial velocity slightly flattens until the rotation angle matches the next blade location. In addition, some small oscillations can be seen in radial velocity.

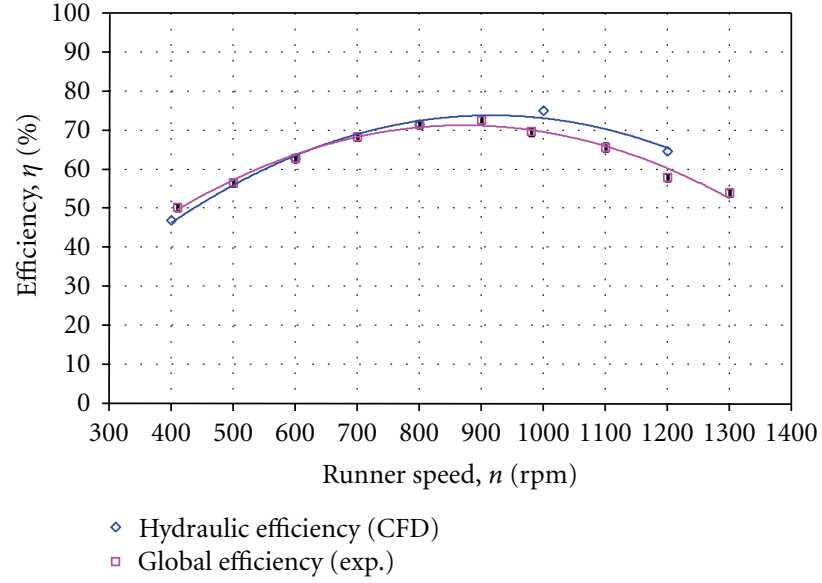

FIGURE 11: Comparison between numerical hydraulic efficiency and experimental global efficiency against runner speed.

Performance Curves. This section focuses on the assessment of numerical and experimental calculations by comparing global performance parameters for different speeds of the turbine. The experimental global efficiency and numerical hydraulic efficiency are related. Further, the percentages of energy transferred in the 1st and 2nd stage are calculated for the design runner speed.

Figure 11 shows the experimental and numerically predicted efficiency values of the turbine for different speeds. The error bars on the experimental results are included. Polynomial tendency curves with maximum values corresponding to the best efficiency speed can be seen. The curves show a similar pattern and for both experimental and numerical cases, the maximum efficiency values of around $900 \mathrm{rpm}$ are detected.

The consistency between the global experimental efficiency and the numerical hydraulic efficiency is relatively good, since the slope and the magnitudes are well predicted. However, numerical efficiency tend to give higher values for runner speeds superior to runner speed design, thus indicating that the efficiency is overpredicted. The maximum relative error was found at $n=1200 \mathrm{rpm}$, about $10 \%$ than measured one. An explanation for the overprediction is, at least partially, that the mechanical efficiency of the turbine is not considered in the numerical calculations and, it rises by increasing the runner speed [22].

Numerical-experimental discrepancies can also be explained by several other causes. First main cause is the numerical approach: homogeneous free surface model without buoyancy. This assumption cannot take into account the segregation between phases due to the gravitational action on the flow. Other causes may concern numerical procedure, mesh refinement dependency, turbulence model, boundary conditions, data processing, and geometric fidelity of the turbine.

Furthermore, the percentages of energy transferred in the 1st and 2nd runner stage for design speed are presented in Table 3. Some experimental researchers have found similar percentages [14-17]. 
TABle 3: Percentages of energy transferred in the 1st and 2nd stage at design conditions.

Energy transfer at design conditions

\begin{tabular}{ll}
\hline 1st runner stage & $68.5 \%$ \\
\hline 2nd runner stage & $31.5 \%$ \\
\hline
\end{tabular}

Qualitative Flow Field Analysis. Contours of volume fraction and water superficial velocity vectors at midspan location for different runner speeds $(400,600,800,1000$, and $1200 \mathrm{rpm})$ are shown in Figure 12. With regard to water volume fraction, a clearly defined free surface interface can be seen between the water flow and the surrounding air. From speed 400 to $1200 \mathrm{rpm}$ differences among the angular sectors occupied by the water flow within the runner, as well as for the water flow that moves forward all the way to the casing outlet, can be observed. Both in the runner as in the casing, the area occupied by the water apparently decreases, whereas the runner speed increases. Certainly, as the water flow areas are smaller, the water flow velocity increases in order to maintain the same flow rate through the turbine. In particular, for $400 \mathrm{rpm}$ the water volume fraction contour presents a well defined 1st and 2nd runner stage.

Moreover, Figure 12 shows water volume fraction contour plots at $1000 \mathrm{rpm}$ and higher, that water starts to flow over the casing walls, mainly over the nozzle wall. Mendoza and Dominicis [18] observed this behavior in their experimental tests. They attributed this behavior to the flow recirculation in the 2 nd stage; the water is dragged by the blades along the suction side and thrown out against the nozzle wall. This behavior is more prominent at $1200 \mathrm{rpm}$.

In the same Figure 12, the water superficial velocity vector plots show that the flow accelerates in the nozzle outlet similar to domain I results. Further, that the crossing flow leaves the 1st stage at different relative flow angles. Moreover, it can be observed that the relative velocity flow vectors at outlet 1st stage $W_{2}$ are different from those at inlet 2nd stage $W_{3}$. Therefore, it is important to mention that through the runner design, the assumption of $W_{2}=W_{3}$ was taken.

For all runner speeds addressed, the water flow when leaving 1st stage shocks with the runner shaft, which is shown in the figure as a major water volume fraction located around the shaft. The explanation is probably an overdesign of the shaft diameter. The consequences of this phenomenon are energy drop in the shock zone, spattering, and changes on the flow direction that enters the 2nd stage of the runner. For runner speed of $600 \mathrm{rpm}$, the total pressure drop around the shaft is depicted in Figure 13.

Furthermore, in relation to the water superficial velocity vectors it is also important to indicate the presence of recirculation flow zones in the interblade flow passages, in particular along the suction side of the blade in both the 1st and 2 nd stages of the blades. These fluid dynamic behaviors are more significant for runner speeds lower than at design conditions. For runner speeds of $400 \mathrm{rpm}$, the recirculation flow zones in the 1st and 2nd stage are depicted in Figure 14.

Another flow zone through the cross-flow turbine significant to mention is indicated in Figure 15, where the total

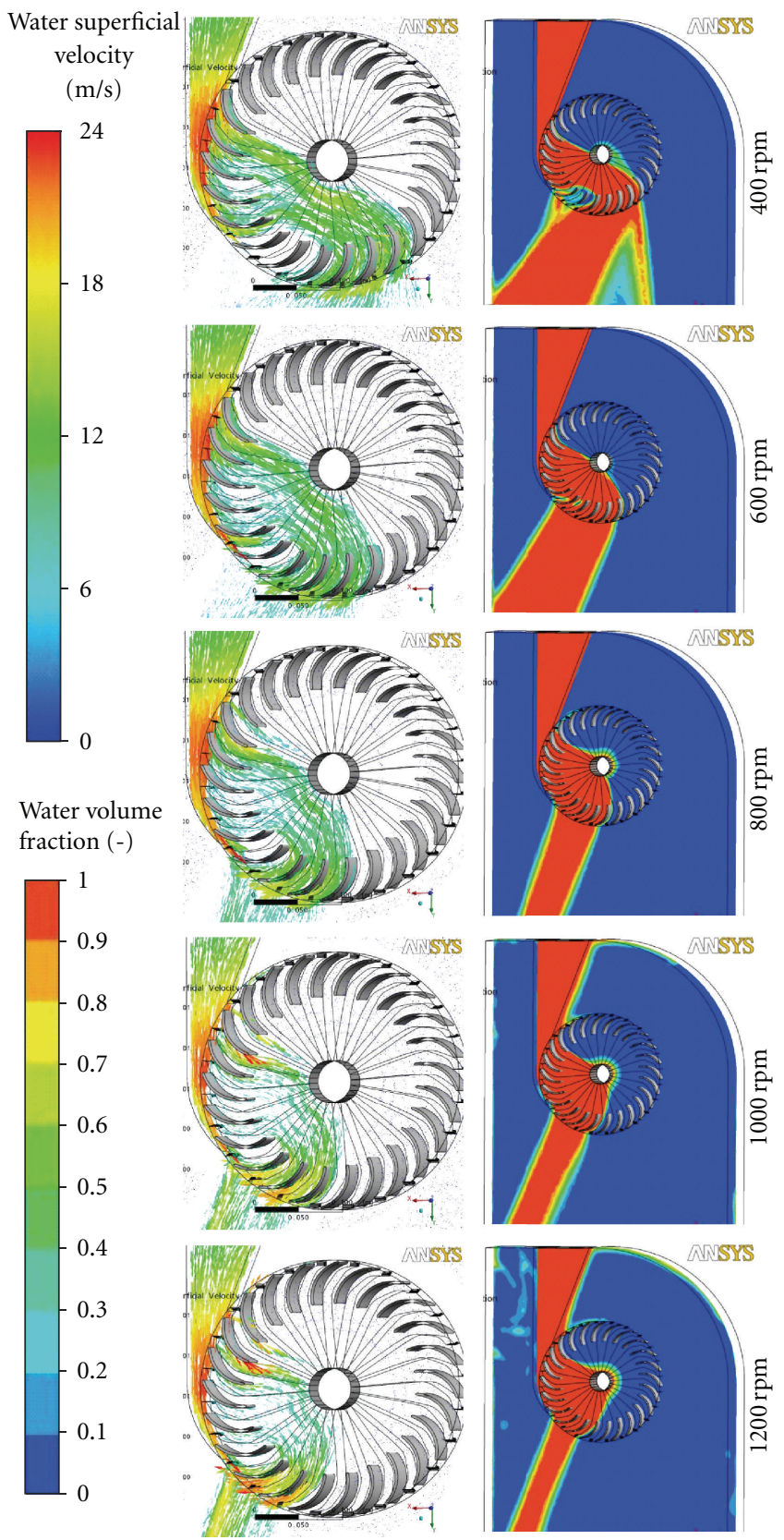

FIGURE 12: Contours of volume fraction and water superficial velocity vectors at midspan from simulated runner speeds $n=400$, $600,800,1000$, and $1200 \mathrm{rpm}$.

pressure and water streamlines are shown at the midspan of the turbine for $1200 \mathrm{rpm}$. The non-cross-flow dragged within the blades is lost in the 2nd stage and leaves without transferring energy.

According to the simulations, the non cross-flow is certainly present for runner speeds greater than at design conditions.

Absolute and Relative Flow Velocity Angles. During the hydraulic design of the runner, an ideal turbine operation condition is assumed. This design is aimed at guaranteeing 


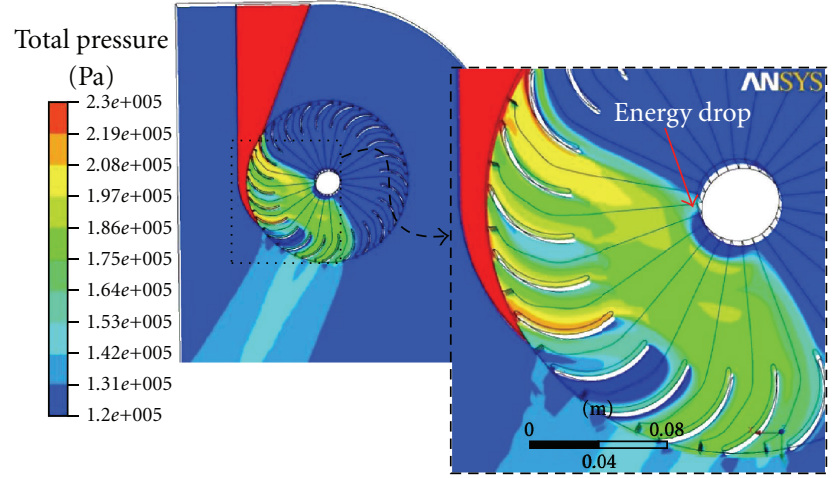

Figure 13: Total pressure contour at midspan of domain nozzle runner casing for runner speed $600 \mathrm{rpm}$.

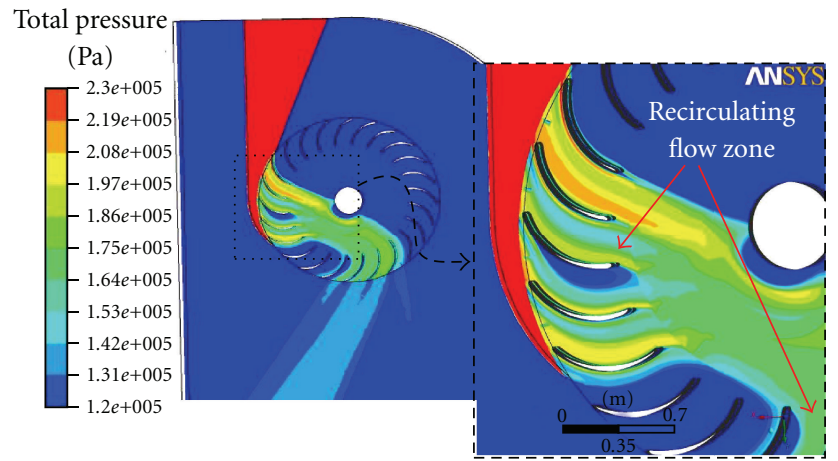

FIGURE 14: Total pressure contour at midspan of domain nozzle and runner casing for runner speed $400 \mathrm{rpm}$.

the greater hydraulic energy transfer. Therefore, knowledge of the velocity triangles or flow direction at the entrance and outlet of each stage of the runner is of vital importance. The study of these variables is quite complex in an experimental test, and so, the CFD tools represent a useful means to this end.

In the following set of figures, the absolute and relative flow velocity angles of the 1st and 2nd runner stage for the design speed are presented. The flow angles are plotted against the rotation angle $\theta$. The rotation angles were normalized with the total angular sector occupied by each stage of the runner. Some the small oscillations can be seen in the plotted flow angles. The numerical grid could count, at least partially, on these oscillations; their impact on the turbine performance is considered minimal according to the grid validation.

In Figure 16, the entrance flow velocity angle $\alpha_{1}$ is plotted as a function of $\theta$ angle. The $\alpha_{1}$ angle has a tendency to decrease with increasing $\theta$ angle until it reaches approximately half of the admission arc. Then, the angle $\alpha_{1}$ gradually tends to rise up to the end of the stage. Significant perturbations on the $\alpha_{1}$ angle with prominent downward peaks can be observed. The sources of this behavior, as commented before, are the periodical impacts of the upstream runner flow field with the leading edge of the runner blades. After each shock

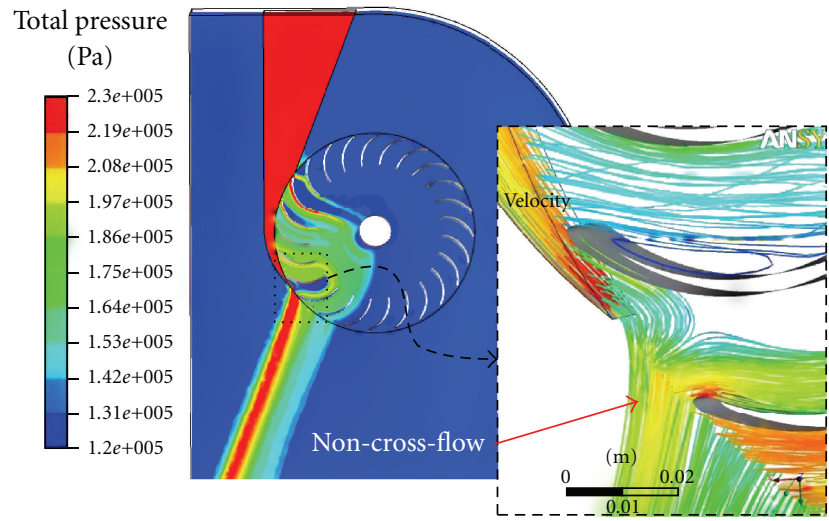

FIGURE 15: Total pressure contour at midspan of domain nozzlerunner-casing for runner speed $1200 \mathrm{rpm}$.

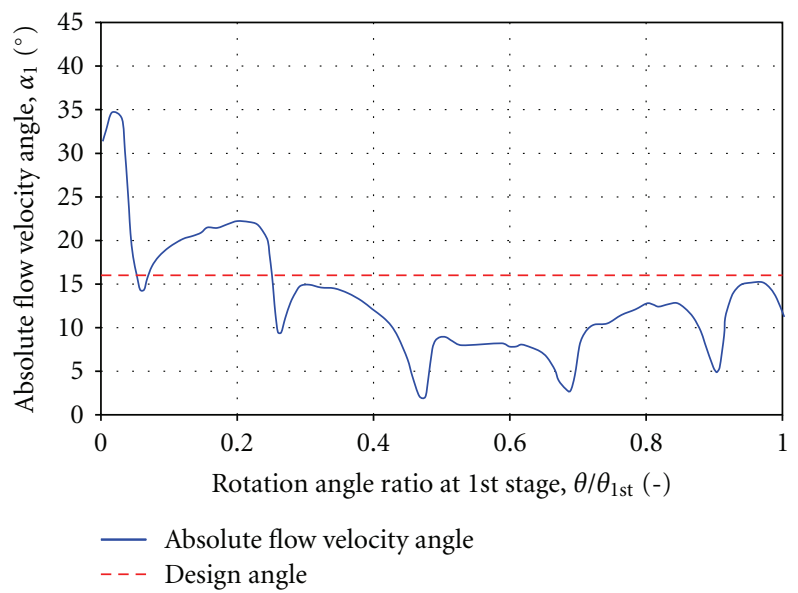

Figure 16: Absolute flow velocity angles of 1st runner stage entrance along the normalized rotation sector at design conditions.

with the blades leading edge, the $\alpha_{1}$ angle flattens slightly until the next blade leading edge location. It is important to remember that the design $\alpha_{1}$ angle is $16^{\circ}$ and even when the $\alpha_{1}$ angles are surrounding this design condition, the hydraulic efficiency of this stage is adversely affected upon this flow condition. Again, the explanation for this flow behavior is probably the standard supposition of potential flow when the nozzle was designed.

In Figure 17, the relative velocity angle at the outlet of 1 st stage $\beta_{2}$ is plotted against $\theta$ angle. The $\beta_{2}$ angle has a tendency to decrease slightly with increasing $\theta$ angle until it reaches approximately $70 \%$ of the admission arc. At this point, the $\beta_{2}$ angle is approximately close to the design condition $\beta_{2}=$ $90^{\circ}$. Then, the $\beta_{2}$ angle quickly descends to zero up to the end of the stage. The explanation is that the progressive interference or meddling of the flow streamlines within the runner become more important with increasing $\theta$ angle for this stage, affecting in that way the flow angle (see Figure 12). As well as for $\alpha_{1}$, significant perturbations on the $\beta_{2}$ angle with prominent downward peaks can be observed. Although this occasion, the sources of this behavior are the periodical flow wakes downstream of 1st stage after each blade. It can 


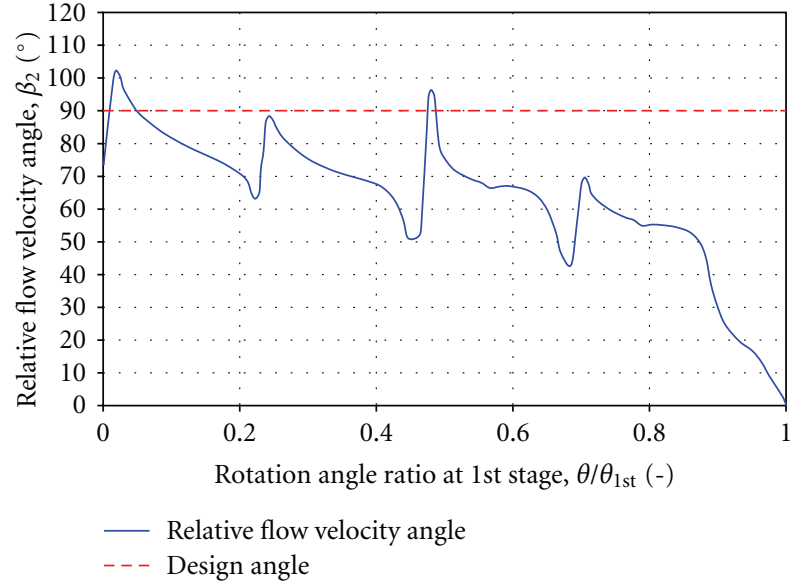

FIGURE 17: Relative flow velocity angles of 1st runner stage outlet along the normalized rotation sector at design conditions.

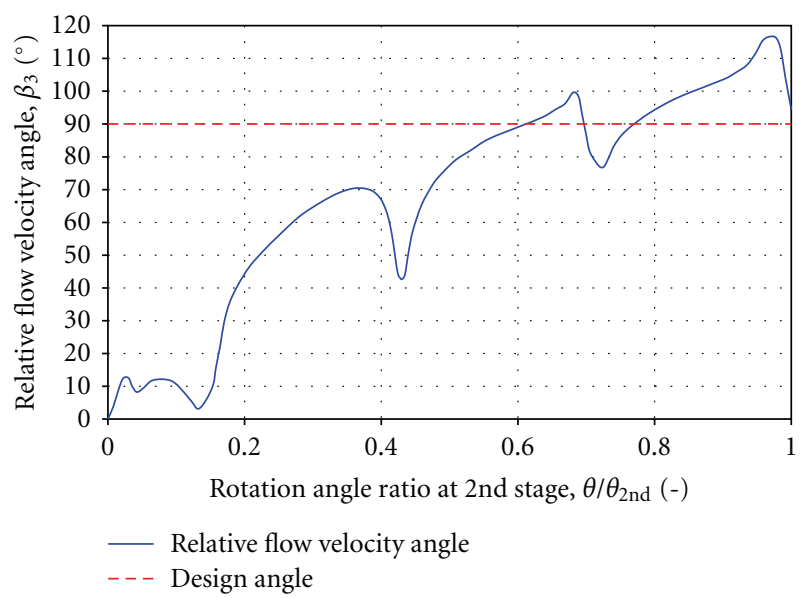

FIgURE 18: Relative flow velocity angles of 2 nd runner stage entrance along the normalized rotation sector at design conditions.

also be mentioned that between those sharp peaks the $\beta_{2}$ angle flattens slightly.

Figure 18 depicts the relative flow velocity angle $\beta_{3}$ against $\theta$ angle. It is noticeable that the $\beta_{3}$ angle has a tendency to ascend with increasing $\theta$ angle all along the 2 nd stage sector. In the figure, it is possible to see that the $\beta_{3}$ angle varies from 0 to $120^{\circ}$. This represents a major flow distortion considering that the design flow condition assumes $\beta_{3}=$ $90^{\circ}$. The reason for this lies in the modification of the flow streamlines that leave the 1st stage and progressively interfere with each other within the runner (see Figure 2). The poor performance of the turbine in the 2nd stage is attributed to this certain deviation regarding the design angle.

Figure 19 shows the outlet flow velocity angle $\alpha_{4}$ for $\theta$ angle. As a consequence of the high alterations of the flow direction $\beta_{3}$ commented above for the entrance of this 2 nd stage, the angle $\alpha_{4}$ presents important disturbances. The $\alpha_{4}$ angle varies between 15 and $140^{\circ}$, most of the fluctuates around $90^{\circ}$ that is the design condition. Moreover, the $\alpha_{4}$

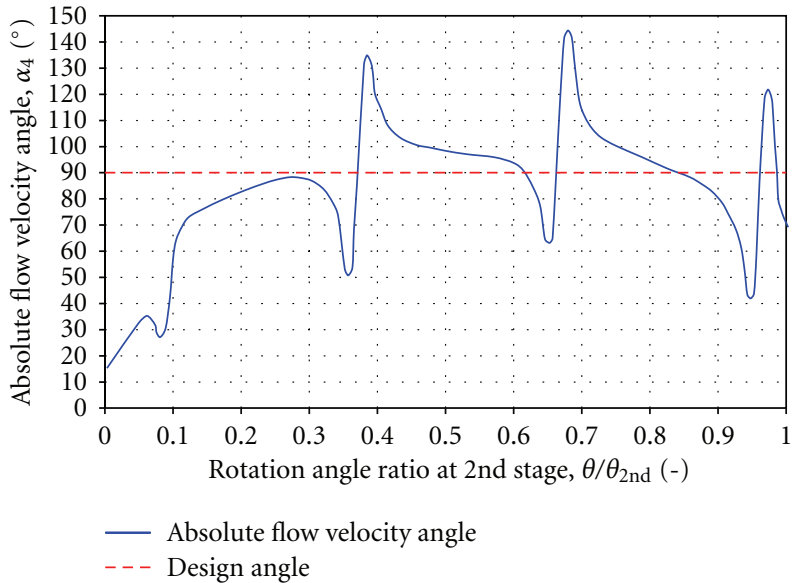

FIGURE 19: Absolute flow velocity angles of 2 nd runner stage outlet along the normalized rotation sector at design conditions.

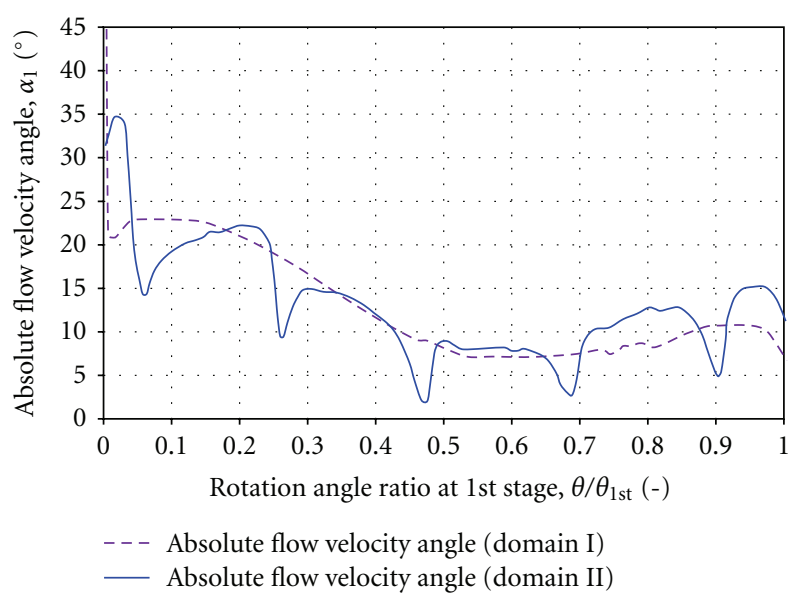

FIgURE 20: Absolute flow angles $\alpha_{1}$ obtained for the numerical domains I and II along the normalized rotation sector at design conditions.

angle flattens slightly after each downward peak produced by the flow wakes presented along the trailing edge of the runner blades.

With regard to the absolute flow velocity angles calculated for domains I and II at the entrance of 1st stage, in Figures 9 and 16, respectively, the comparison of both alternative modeling approaches is depicted in Figure 20. It can be observed in the figure that the agreement between the tendencies of each numerical prediction is generally very good apart from the downward peaks presented in domain II calculations. Therefore, a good average approach of the $\alpha_{1}$ angle can be achieved by simulating the simpler domain I, that is, without considering the runner. This represents a significant lower computational effort.

\section{Conclusions}

Using CFD techniques, it was possible to simulate the behavior of the 3D steady state free surface flow (water-air) 
inside the nozzle-casing assembly of the turbine, being able to visualize the flow field and to obtain the flow angles along the nozzle outlet. It was found that the flow angles along the nozzle outlet $\alpha_{1}$ that would come into the 1st stage of the runner slightly varies from $23^{\circ}$ to $7^{\circ}$ along the rotation angle $\theta$, passing through the design condition angle $\alpha_{1}=16^{\circ}$. The deviation of the $\alpha_{1}$ angle is explained with the potential flow condition assumed when the nozzle is designed. The water volume fraction was also addressed. The results show that the admission arc is full of water from $5^{\circ}$ of the rotation angle.

A full 3D-CFD steady state flow simulation of the crossflow turbine was performed which included: nozzle, runner, shaft, and casing. The simulations were carried out using a homogeneous free surface model. The global experimental efficiency and the numerical hydraulic efficiency were compared for nominal flow at different speeds. The overall agreement was good apart from the speeds higher than $800 \mathrm{rpm}$, where the numerical predictions are higher. The explanation for the overprediction is probably that the mechanical efficiency of the turbine is not considered in the numerical calculations and it rises by increasing the runner speed. Another reason could lie in the numerical mesh, turbulence model $k-\varepsilon$ and homogeneous free surface model without buoyancy. The percentages of energy transfer in the 1st and 2nd stage were addressed for the design speed. The results show that $68.5 \%$ percent of the energy transferred occurs in the 1st stage, and the remaining 31.5\% is transferred in the 2nd stage. In addition, velocity, water volume fraction and pressure fields at midspan were analyzed for the runner speeds $(400,600,800,1000$, and $1200 \mathrm{rpm})$. Fluid dynamic phenomena as shocks with the runner shaft, recirculation flow zones in the interblade flow passages and non-cross-flow were recognized. Further, it was possible to determine quantitatively the 1st and 2nd stage of the runner at nominal speed by considering the variation of the radial water velocity and water volume fraction along a specific rotation sector at the runner inner diameter.

At the design runner speed, the absolute and relative flow velocity angles of the 1st and 2nd runner stage were addressed quantitatively. The results were shown against the normalized rotation angles occupied by each stage of the runner. For all flow angles addressed, were found downward peaks attributed to the location of the runner blades, at either the leading or trailing edge of the blades. This perturbs significantly the flow angles and directly affects the hydraulic efficiency of the runner stages. The observed trends of the flow angles are not an obvious fact, as the flow angles should tend to a theoretical angle. The spanwise variations of the angles vary from one to another but, it could be said that the flow angle that better tends to the design conditions is $\alpha_{1}$ since the water flow coming to the 1st stage is controlled by the nozzle. The worst deviation to the design condition is obtained for $\beta_{3}$ angle that should be close to $90^{\circ}$. The reason lies in the modification of the flow streamlines that leave the 1st stage and progressively interference with each other within the runner.

The numerical studies of the flow angle at runner entrance $\alpha_{1}$ revealed that the simulation the nozzle-casing assembly represents an attractive alternative to obtain it, with regard to the other numerical approach that takes into account the runner of the turbine. Using the simpler flow domain nozzle-casing, the numerical calculations can be simplified considerably and thus the CPU time.

\section{Nomenclature}

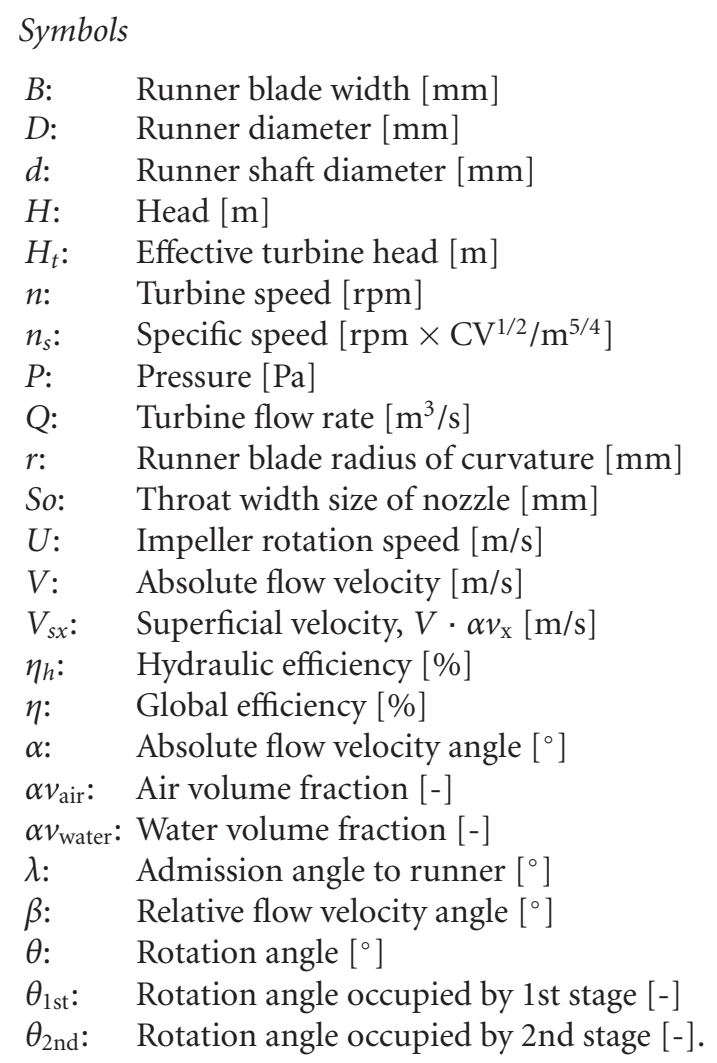

\section{Subscripts}

1: Runner blade inlet (1st stage)

2: Runner blade outlet (1st stage)

3: $\quad$ Runner blade inlet (2nd stage)

4: $\quad$ Runner blade outlet (2nd stage)

ins: Inside

out: Outside

$r$ : Radial component

$u$ : Rotation component.

\section{Abbreviations}

CFD: Computational fluid dynamics

$B E P$ : Best efficiency point.

\section{References}

[1] M. Asuaje, F. Bakir, S. Kouidri, F. Kenyery, and R. Rey, "Numerical modelization of the flow in centrifugal pump: volute influence in velocity and pressure fields," International Journal of Rotating Machinery, vol. 2005, no. 3, pp. 244-255, 2005.

[2] H. Nilsson and L. Davidson, "Validations of CFD against detailed velocity and pressure measurements in water turbine runner flow," International Journal for Numerical Methods in Fluids, vol. 41, no. 8, pp. 863-879, 2003. 
[3] C. A. Mockmore and F. Merryfield, The Banki Water Turbine, Bulletin Series no. 25, Engineering Experiment Station, Oregon State System of Higher Education, Oregon State College, Corvallis, Ore, USA, 1949.

[4] F. Kenyery and J. Alcala, "Experimental study of an interior deflector in cross flow turbines," in Proceedings of the 2nd European Conference on Turbomachinery-Fluid Dynamics and Thermodynamics, pp. 503-512, Antwerpen, Belgium, March 1997.

[5] N. H. C. Pereira and J. E. Borges, "Study of the nozzle flow in a cross-flow turbine," International Journal of Mechanical Sciences, vol. 38, no. 3, pp. 283-302, 1996.

[6] A. Marchegiani and M. Montiveros, "Efecto de la geometría del inyector en una turbina tipo Banki," in 11th Encuentro Latino Americano y del Caribe Sobre Pequeños Aprovechamientos Hidroenergéticos, Valparaíso, Chile, November 2005.

[7] F. Arzola, C. Rodriguez, J. Martin, J. De Andrade, A. Vásquez, and M. Asuaje, "Technical assessment for overhaul project in small hydro power plant," in Proceedings of the 24th Symposium on Hydraulic Machinery and Systems (IAHR '08), Iguassu, Brasil, October 2008.

[8] S. Chávez and C. Vera, "Modelamiento de los parámetros de funcionamiento de la Turbina Hidráulica de flujo cruzado aplicando el método de elementos finitos," in 8th Congreso Iberoamericano de Ingeniería Mecánica8th Congreso Iberoamericano de Ingeniería Mecánica, Cusco, Perú, October 2007.

[9] J. Fukutomi, Y. Nakase, M. Ichimiya, and H. Ebisu, "Unsteady fluid forces on a blade in a cross-flow turbine," JSME International Journal B, vol. 38, no. 3, pp. 404-410, 1995.

[10] J. Fukutomi, Y. Senoo, and Y. Nakase, "A numerical method of flow through a cross-flow runner," JSME International Journal B, vol. 34, no. 1, pp. 44-51, 1991.

[11] Y. Choi, J. Lim, Y. Kim, and Y. Lee, "Performance and internal flow characteristics of a cross-flow hydro turbine by the shapes of nozzle and runner blade," Journal of Fluid Science and Technology, vol. 3, no. 3, pp. 398-409, 2008.

[12] S. Khosrowpanah, A. A. Fiuzat, and M. L. Albertson, "Experimental study of cross-flow turbine," Journal of Hydraulic Engineering, vol. 114, no. 3, pp. 299-314, 1988.

[13] A. A. Fiuzat and B. P. Akerkar, "The use of interior guide tube in cross flow turbines," in Proceedings of the International Conference on Hydropower (WATERPPOWER '89), vol. 2, pp. 1111-1119, August 1989.

[14] A. A. Fiuzat and B. P. Akerkar, "Power outputs of two stages of cross-flow turbine," Journal of Energy Engineering, vol. 117, no. 2, pp. 57-70, 1991.

[15] R. D. Venkappayya and M. A. Nadim, "An experimental investigation of cross flow turbine efficiency," Journal of Fluids Engineering, vol. 116, no. 3, pp. 545-550, 1994.

[16] Y. Nakase, J. Fukutomi, T. Watanabe, T. Suetsugu, T. Kubota, and S. Kushimoto, "A study of cross-flow turbine: effects of nozzle shape on its performance," in Proceedings of the ASME Conference on Small Hydro Power Fluid Machinery, pp. 13-18, Phoenix, Ariz, USA, November 1982.

[17] D. G. Shepherd, Principles of Turbomachinery, Macmillan, New York, NY, USA, 1956.

[18] G. Mendoza and R. De Dominicis, Design and construction of a Banki turbine, Engineering thesis, Metropolitan University, London, UK, 1989.

[19] H. Grotjans and F. R. Menter, "Wall functions for general application CFD codes," in Proceedings of the 4th European Computational Fluid Dynamics Conference (ECCOMAS '98), pp. 1112-1117, John Wiley \& Sons, Athens, Greece, September 1998.
[20] P. Zwart, "Numerical modelling of free surface and cavitating flows," in Proceedings of the Industrial Two-Phase Flow (CFD '05), VKI Lecture Series, pp. 1-25, Brussels, Belgium, May 2005.

[21] CFX-5 Solver and Solver Manager, "Homogeneous multiphase and free surface flow," 2005, http://hikwww2.fzk.de/hik/orga/ hlr/AIX/software/cfx/flow/cfx_models/free_surface.pdf.

[22] CFX-5 Solver Modelling, "Domain interface modelling," 2005, http://iceberg.shef.ac.uk/docs/cfx-pdf/solver_modelling/DommainInterfaceModelling.pdf. 

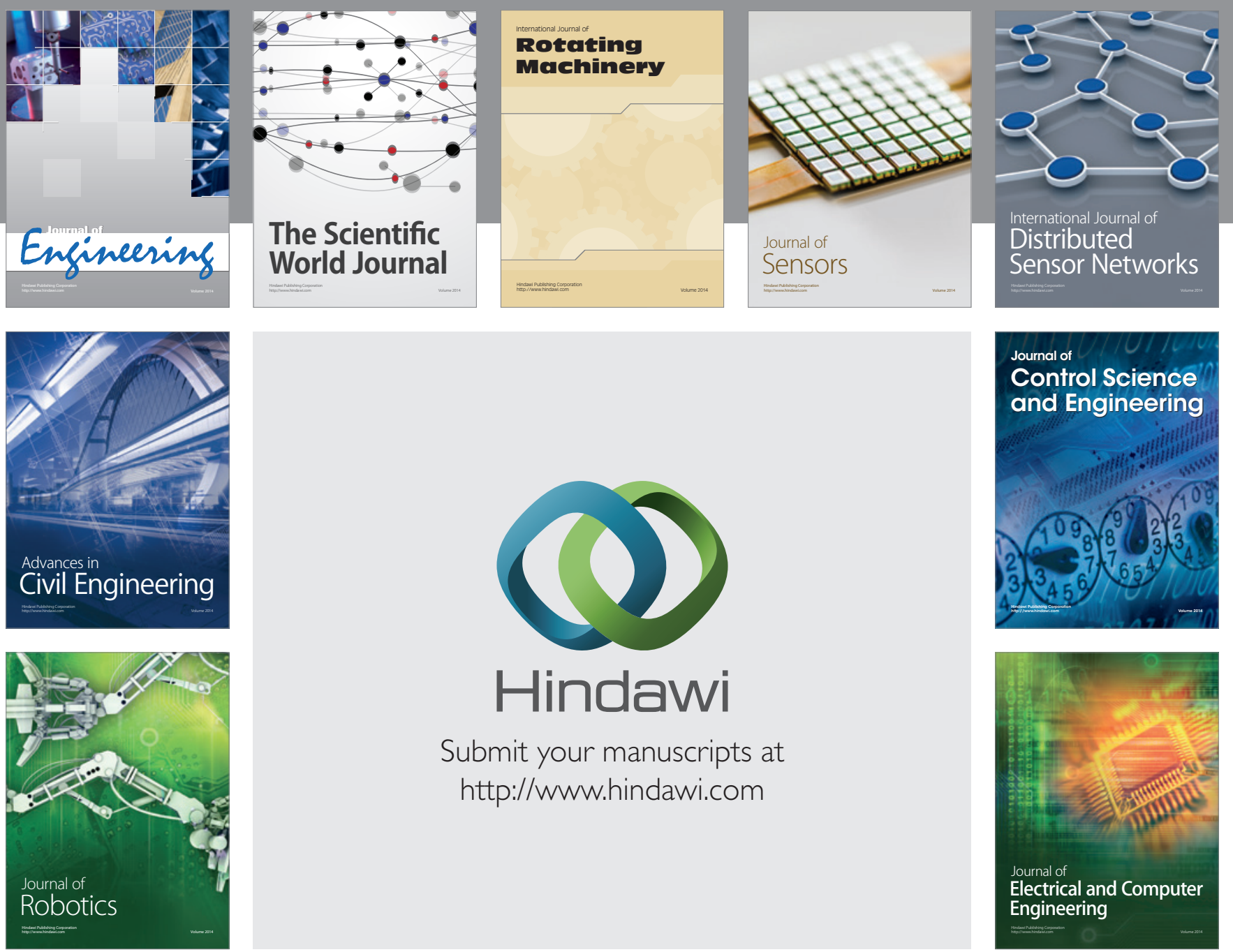

Submit your manuscripts at

http://www.hindawi.com
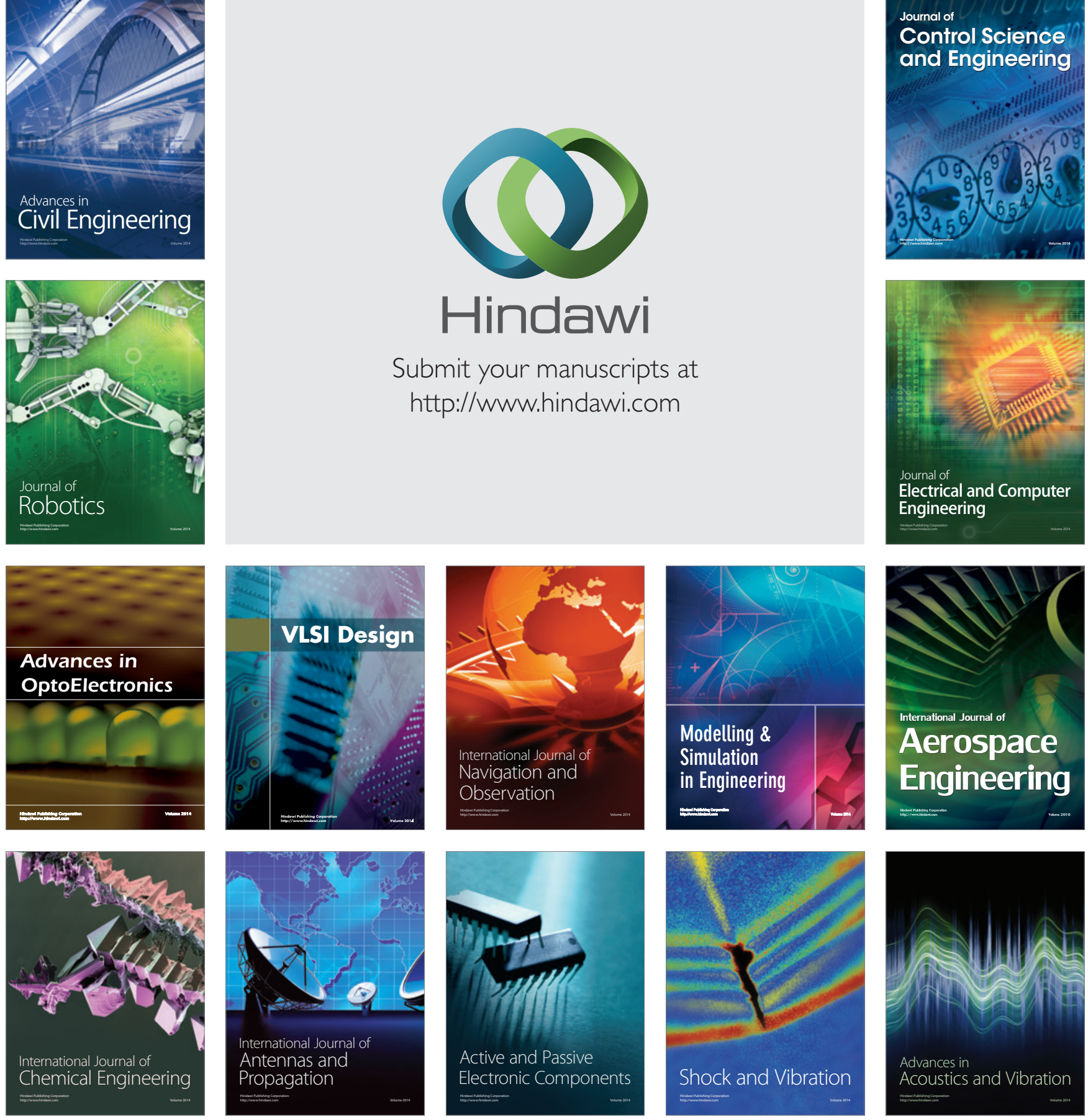